\title{
Preface to the Fifth Edition
}

\author{
FIFTY YEARS IN THE WILDERNESS
}

Timing, it is often said, is everything. The axiom is a reminder to me that while this book may be a good one, even, some generously say, a "classic," it is indisputably lucky. I caught the wilderness wave as it began to crest and became the beneficiary of the very intellectual revolution I described. As I write these words, the fiftieth anniversary of the Wilderness Act approaches on September 3 , 2OI 4 . It will soon also be a half century since the summer of I 964 , when I completed the University of Wisconsin dissertation from which this book developed. But if, as an Outside magazine poll claimed, Wilderness and the American Mind was one of the books that changed our world, then it must also be recognized that the world was ready to be changed.

This book really began a long way from the wilderness, in an apartment on the island of Manhattan in the heart of New York City. It doesn't get much more urban than where I grew up! I could not see a single living thing from my bedroom window, which opened to a narrow alley and a solid brick wall. Once in a while a pigeon feather would flutter down from the rooftop terrace ten floors above. There were no stars at night in New York, and it was never really quiet. Yet this was precisely the context that nourished interest in wild places. Theodore Roosevelt's family raised him about ten blocks away. Wilderness appreciation, in short, was an urban, not a frontier, product. If I had hailed from Moab, Utah, where I later lived for a while, I might well have chosen to write about cities in American thought.

Yet as it happened, in 1960 , as a beginning history graduate student at the University of Wisconsin, I approached Professor Merle Curti with a proposal to focus my doctoral research on wilderness. ${ }^{1}$ Assuming, quite logically, that wilderness had nothing to do with human beings, the professor gently suggested that I had come to the wrong campus building. Wouldn't the geology or biology de-

I . One of Merle Curti's books, The Groweth of American Thought, had won the Pulitzer Prize for history in 1944 . 
partment be a better fit for my project? In the few minutes left in our conversation I managed to make the case that wilderness was not so much a place as a feeling about a place - a perceived reality, a state of mind. So why not a history of the wilderness idea?

As I moved from Madison, Wisconsin, in I964 to teach, first at Dartmouth College and later at the University of California Santa Barbara, and prepared a manuscript for publication, sweeping changes in American values and attitudes were fueling growing interest in wilderness and its preservation. We boil down these changes into easy phrases such as I 960 s environmentalism, the ecological perspective, and the counterculture. Rachel Carson launched an extraordinary decade with a New Yorker article on insecticides that, in 1962 , became the book Silent Spring. Within a few years another book that had languished since its publication in I 949 became a best-seller: Aldo Leopold's strangely titled $A$ Sand County Almanac. It changed the definition of ethics for a generation of conservation-minded Americans. The Wilderness Act (I 964) added substance to Bob Dylan's observation about changing times. Four years later came the defeat of plans to dam the Colorado River in the Grand Canyon. In I 969 Neil Armstrong looked back at "spaceship earth" from the moon. The first Earth Day and the National Environmental Policy Act followed in I970. In the next three years the Marine Mammal Protection Act and the Endangered Species Act showed that American politics and culture really did understand Rachel Carson's message ten years earlier.

Yale University Press published the first edition of Wilderness and the American Mind in I 967 . The paperback edition cost all of \$2.25! I concluded the book with speculation on the irony inherent in the rising popularity of wilderness: it could be loved to death. The next two editions (I973 and I982) expanded the story to include the battles over the Grand Canyon dams and the status of wild country in Alaska. I also wrote about the meaning of wilderness for late twentieth-century American civilization and looked more deeply at the somewhat oxymoronic phenomenon called wilderness "management." In addition I examined the international significance of the American invention of national parks and legally protected wilderness.

In the concluding pages of the 1982 book I began to explore the future for wilderness on a rapidly changing planet. I looked at the need to control human population and sprawl and to find "be- 
neficent forms of centralization and the technologies that would make them feasible." I was also interested in alternatives to the anthropocentric arguments that had anchored the early appreciation of wilderness. Wild places had been valued and protected for people. Whether involving scenery, recreation, or the economics of nature tourism, wilderness seemed to be all about us. But a newer ecocentric rationale valued wilderness as a symbol of the capacity for restraint on the part of a species notorious for its selfishness. It is relevant that at this time I was writing another book: The Rights of Nature: A History of Environmental Ethics (1989). It was a history of the idea that nature had intrinsic rights and that ethics should extend to a wider community. I was curious whether American natural rights ideology, taken to its logical limits, could lead some philosophers and activists to articulation of the rights of nature. This research helped me understand the significance of wilderness preservation as a way to share the planet, and the evolutionary process, with other species.

By the time of the fourth edition in 200I, I was discussing the idea of reducing human impact on the planet with a new name: "Island Civilization." 3 The term occurred to me while looking at those familiar maps on which designated wilderness appeared as little green squares in a sea of country that humans had modified. Why not start thinking about turning that around? With the aid of technologies that might over time enable our species to reduce, rather than increase, our impact on nature, we could endeavor to put boundaries around civilization rather than wilderness. The epilogue in this fifth edition discusses those possibilities. Island Civilization, I think, is one way to fulfill the evolutionary potential of our species without compromising or eliminating that of the other species with which we ought to share the planet.

It seems appropriate at this point to pick up a few ideas from the opening of the 1967 first edition and introduce some new thoughts about the origin and meaning of the wilderness concept. Wilderness was the basic ingredient of American culture. From the raw

2. Wilderness and the American Mind (3rd ed. New Haven, Conn., I982), p. $38_{3}$.

3. My first articulation of this concept was "Island Civilization: A Vision for Planet Earth in the Year 2992," Wild Earth, I (Winter, I99I-92), 2-4. The most recent iteration is "Island Civilization: A Vision for Human Inhabitance in the Fourth Millennium," in Life on the Brink: Environmentalists Confront Overpopulation, ed. Philip Cafaro and Eileen Christ (Athens, Ga., 201 2), pp. 301 -I 2. 
materials of the physical wilderness Americans built a civilization. With the idea of wilderness they sought to give that civilization identity and meaning. Today wild places enjoy widespread popularity. There is even fear of destruction by too many enthusiastic visitors and consequent limitations on recreational use. Yet for most of their history Americans regarded wilderness as a moral and physical wasteland fit only for conquest and fructification in the name of progress, civilization, and Christianity. The remarkable transformation that has replaced this attitude with appreciation is the concern of this book. It is also one of the most revolutionary changes in the history of ideas about nature.

The roots of the story lie in the fact that civilization created wilderness. For the nomadic hunters and gatherers who composed our species for most of its history, "wilderness" was a meaningless concept. Everything natural was simply habitat. People understood themselves to be part of a seamless community. Nothing was "wild" because nothing was tamed. Lines began to be drawn - on the land and in human minds - with the advent of herding, agriculture, and settlement some ten thousand years ago. After that it made sense to think of those parts of nature that had their own "will" and those that had been bent to follow the will of people. The word "wild" is a contraction of "willed"; literally, wilderness means self-willed land. ${ }^{4}$

With this concept in place, distinctions between controlled (domesticated) and uncontrolled plants and animals became meaningful. So did the concept of controlled space such as fenced fields, pastures, and walled towns. For the first time humans understood themselves to be distinct from and, they reasoned, better than the rest of nature. A haze of tempting ideas swirled up with the village smoke. It was possible to think of people as masters or owners, not just members, of the life community. There were now survival reasons to order and control nature. Wilderness became dangerous,

4. In the first, 1967 edition of this book I used the term "self-willed" but applied it mainly to animals (see below, pp. 1-2). In r 983 Jay Vest read a paper at the Third World Wilderness Conference which suggests that in early Celtic cultures "wilderness" signified land that had its own "will power": Jay Hansford Vest, "Will of the Land: Wilderness Among Primal Indo-Europeans," Environmental Revieal, 9 (1985), 323-29. The essential idea is that wilderness means a place uncontrolled by the pastoral civilizations that developed along with the phasing out of hunting and gathering. 
even evil. Why not make the crooked straight and the rough places plain? Why not insert into religion the idea that God has "given" nature to man to conquer? The capstone of these civilized dreams was the idea of paradise, an environment perfectly suited to human desires. The opposite of paradise, of course, was wilderness. It easily became an adversary, a target and an object for exploitation. These were the understandable biases exhibited by the pastoral cultures of the Bible, and they were a major part of the intellectual baggage carried to a New World where suddenly wilderness was very real and very frightening.

But what about the Indians? Obviously there were people in North America when the European settlers arrived. They were, however, still largely hunters and gatherers who had not drawn those lines between themselves and self-willed nature. For example, Chief Luther Standing Bear of the Ogalala Sioux explained that his people "did not think of the great open plains ... as "wild.' Only to the white man was nature a "wilderness." "5 The whites also had a word for the natives: "savages." They were to be conquered and transformed (or eliminated), just like the wild country. Regardless of what we might think about it today, Indians made the New World a greater, not a lesser, wilderness for the pioneer pastoralists.

American attitude toward wilderness is old and complex. It was always the biggest fact on every frontier. The short summary of what we are going to explore in this book is that the wilderness idea was born in a context of fear and loathing, and that the old biases have died hard. Appreciation of wilderness is recent and incomplete. Only when they had largely won the battle against the wild (marked in some ways by the so-called ending of the frontier in the census of I 890) did Americans reach out to help their traditional adversary to its feet. Now, more than a century later, many think the challenge is no longer the conquest of the wilderness but rather of the self-destructive tendencies of an excessive civilization. It is even conceivable that the new frontiersmen engaged in this critical task will find, in the wilderness that remains, one of their most important allies.

In this fifth edition of my story I have opted to let the prologue and core chapters of the original 1967 book and the 1973 and 1982

5. Standing Bear, Land of the Spotted Eagle (Boston, 1938), p. $3^{8}$. 
expansions stand. It is appropriate to acknowledge again the late Merle Curti, who took a gamble half a century ago on a big-picture thesis that initially did not even seem to be a part of "history." I am also grateful to Sarah Miller and Yale University Press for keeping the book alive and to readers, academic and activist alike, who have valued it for so many years.

Crested Butte, Colorado

fune 2013 